Foro Interno. Anuario de Teoría Política

ISSN: $1578-4576$

\title{
Antecedentes para una psicología de las masas presentes en el pensamiento de Niccolò Machiavelli
}

\author{
Corina Inés Branda ${ }^{1}$
}

Recibido: 10 de febrero de 2018 / Aceptado: 19 de julio de 2019

Resumen. El artículo rastrea en dos de los textos importantes de la obra de Niccolò Machiavelli (14691527): El príncipe y los Discursos sobre la primera década de Tito Livio, elementos conceptuales inherentes a la noción psicoanalítica psicología de las masas. En el pensamiento del florentino es dable hallar cierta teoría psicológica, la cual es concebida como expresión de deseos y afectos humanos, a la cual el autor arriba a partir de una aguda observación empírica y del conocimiento del pasado. Machiavelli analiza la ciudad como un campo de deseos en pugna, el deseo del pueblo de no ser oprimido y el de los nobles de ambición ilimitada. En el análisis que despliega el autor sobre estos deseos en conflicto, pero sobre todo en la relación entre el príncipe, los nobles y el pueblo, así como en la caracterización que realiza de éste, es posible hallar elementos en ciernes de la psicología de las masas desarrollos luego por el psicoanálisis freudiano.

Palabras claves: Deseos; masa; pueblo; psicología de las masas.

\section{[en] The Background of Mass Psychology in Niccolò Machiavelli's Thought}

\begin{abstract}
This article traces certain conceptual elements inherent to the psychoanalytic notion of mass psychology in two of the most important works of Niccolò Machiavelli (1469-1527): The Prince and the Discourses on the First Decade of Titus Livy. It is possible to find in the works of this Florentine a psychological theory that offers an expression of human desires and affections. The author bases this form of thought on acute empirical observation and knowledge of the past. Machiavelli analyzes the city as a locus of conflicting desires: the desire of the people not to be oppressed versus the unlimited ambition of the nobles. It is possible to find incipient elements typical of mass psychology developed later by Freudian psychoanalysis in Machiavelli's account of conflicting desires, but above all in the relationship between the prince, the nobles and the people, as well as in the characterization of the latter. Keywords: Desires; masses; people; mass psychology.
\end{abstract}

Cómo citar: Corina Inés Branda, "Antecedentes para una psicología de las masas presentes en el pensamiento de Niccolò Machiavelli”: Foro Interno. Anuario de Teoría Política, vol. 19 (2019), pp. 93-108.

Facultad de Ciencia Política y Relaciones Internacionales, Universidad Nacional de Rosario (República Argentina)

E-mail: corinaines13@yahoo.com.ar 


\section{Introducción}

Maquiavelo, en el curso de este proceso, evidenció una comprensión de la naturaleza de la masa política mayor que cualquier pensador anterior al siglo XIX².

El propósito principal que inspira este trabajo es explorar una ruta un tanto intransitada en el pensamiento de Niccolò Machiavelli (1469-1527) desplegada en El príncipe y los Discursos sobre la primera década de Tito Livio3; a saber, la presencia de elementos inherentes a la psicología de las masas, de acuerdo a la noción que fue posteriormente elaborada por el psicoanálisis freudiano. La exploración se ciñe a los dos textos mencionados del corpus maquiaveliano porque es en ellos en los cuales el pensamiento del florentino sobre psicología colectiva está desarrollado y fundado con mayor precisión y extensión.

El trabajo tiene la intención de contribuir a la investigación de un expediente que no ha sido profundamente trabajado en el Machiavelli. Conforme al relevamiento efectuado del estado del arte no se hallaron estudios desde la perspectiva que se propone desplegar en este trabajo. Se encontraron escasos escritos que hacen alusión a la relación entre Machiavelli y el concepto de psicología de las masas o psicología política, pero éstos no profundizan ni argumentan desde la propia producción del autor florentino.

Los análisis de Machiavelli suponen "cierta psicología" o "teoría psicológica", la cual se enfoca, especialmente, en el comportamiento, como una suerte de psicología comportamental o psicología del comportamiento. "La psicología a la que recurre Maquiavelo podría calificarse de 'experimental', si se entiende por ello una psicología de las conductas pensadas como expresión de los deseos y los afectos"”.

Dicho conocimiento sobre la psiquis humana es insoslayable para el análisis político, vale decir el análisis del poder en la esfera pública. El mismo es recopilado por Machiavelli a partir de un ejercicio agudo de observación junto al conocimiento aportado por los hombres del pasado, "en particular de las grandes mentes de la antigüedad, los sabios cuya compañía (como dice en su célebre carta a Vettori) busca cuando escapa de las ocupaciones triviales de la vida diaria". En otros términos, su método es una combinación de observación empírica y conocimiento de la historia, del cual extrae leyes generales, de validez universal. Y, en lo que al alma humana se refiere, el autor de El príncipe advierte leyes generales de la conducta que echan por la borda cualquier modelo idealizado que del hombre se esgrima. El florentino está profundamente convencido de haber dado con una comprensión cabal del hombre, de cómo éste fue, es y será.

2 Sheldon S. Wolin, "Maquiavelo: Actividad política y economía de la violencia”, en Politica y perspectiva. Continuidad y cambio en el pensamiento político occidental, Amorrortu, Buenos Aires, 1960, p. 248.

3 Ambos libros, al decir de Skinner citando a Geerken, deben considerarse como aspectos interdependientes de una visión orgánicamente unificada. Véase Quentin Skinner, Los fundamentos del pensamiento politico moderno. El Renacimiento I, Fondo de Cultura Económica, México, 1985.

$4 \quad$ Pierre Ansart, Los clínicos de las pasiones políticas, Ediciones Nueva Visión, Buenos Aires, 1997, p. 108.

5 Isaiah Berlin, "La originalidad de Maquiavelo", en El estudio adecuado de la humanidad. Antología de ensayos, Fondo de Cultura Económica, Madrid, 2009, pp. 99-100. 


\section{¿Naturaleza humana o humores diversos (umori diversi)?}

Claude Lefort (1924-2010), en El arte de escribir y lo politico ${ }^{6}$, afirma que Machiavelli, más que detenerse en plantear una concepción sobre la naturaleza humana, a él le interesan aspectos psicológicos-comportamentales de ciertos grupos sociales. Es por ello que la pregunta en torno a si los hombres son o no son todos malos, si efectivamente existe una naturaleza humana malvada no es de interés para el propio autor según el mismo Lefort.

Siguiendo a Lefort, la obstinación por definir, por plantear una concepción sobre la naturaleza humana en Machiavelli hará visibles algunas contradicciones. Por ejemplo, en El príncipe, en el capítulo XVII, Machiavelli afirma: "Porque de la generalidad de los hombres se puede decir esto: que son ingratos, volubles, simuladores, cobardes ante el peligro y ávidos de lucro"”.

Más adelante, en el capítulo XXIII del mismo texto, el florentino expresa: "Y es imposible hallar otra clase de consejos, porque los hombres se comportan siempre mal mientras la necesidad no los obligue a lo contrario"s.

En los Discursos sobre la primera década de Tito Livio, en el capítulo 3 del Libro I, el autor afirma:

...es necesario que quien dispone una república y ordene sus leyes presuponga que todos los hombres son malos, y que pondrán en práctica sus perversas ideas siempre que se les presente la ocasión de hacerlo libremente: y aunque alguna maldad permanezca oculta por un tiempo, por porvenir de alguna causa escondida, que, por no tener experiencia anterior, no se percibe, siempre la pone al descubierto el tiempo, al que llaman padre de toda verdad ${ }^{9}$.

En el mismo capítulo del texto mencionado, Machiavelli expresa:

...los hombres solo obran bien por necesidad, pero donde se puede elegir y hay libertad de acción se llena todo, inmediatamente, de confusión y desorden. Por eso se dice que el hambre y la pobreza hacen ingeniosos a los hombres y las leyes los hacen buenos ${ }^{10}$.

En el capítulo 9 de los Discursos encontramos la siguiente afirmación relacionada al organizador de una república:

Si es prudente y virtuoso, también evitará dejar en herencia a otro la autoridad que ha conseguido, pues, como los hombres son más inclinados al mal que al bien, podría su sucesor usar ambiciosamente aquello que él ha empleado virtuosamente ${ }^{11}$.

Ahora bien, en el capítulo IX de El príncipe el florentino sostiene: "Por otra parte, no puede honradamente satisfacer a los grandes sin lesionar a los demás, pero, en

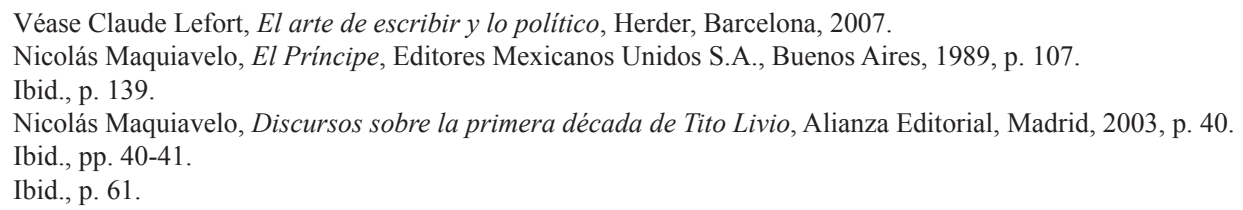


cambio, puede satisfacer al pueblo, porque la finalidad del pueblo es más honesta que la de los grandes, queriendo éstos oprimir y aquél no ser oprimido"12, agregando luego que si el príncipe nuevo sabía mandar, dar ánimo a sus súbditos y ser hombre de corazón nunca le faltará el apoyo del pueblo.

En los Discursos, en el capítulo 5, se encuentra la siguiente afirmación:

Y, sin duda, observando los propósitos de los nobles y de los plebeyos, veremos en aquéllos un gran deseo de dominar, y en éstos tan solo el deseo de no ser dominados, y por consiguiente mayor voluntad de vivir libres, teniendo menos poder que los grandes para usurpar la libertad ${ }^{13}$.

En el capítulo VI de El príncipe, Machiavelli afirma:

Hay que agregar, además, que los pueblos son tornadizos; y que, si es fácil convencerlos de algo, es difíciles mantenerlos fieles a esa convicción, por lo cual conviene estar preparados de tal manera que, cuando ya no crean, se los pueda hacer creer por la fuerza ${ }^{14}$.

Lefort sostiene que en estas citas Machiavelli no se está refiriendo a la naturaleza humana, sino más bien a la ciudad. Y la respuesta se deja ver, tanto en El príncipe, capítulo IX, como en los Discursos, capítulo 4 del Libro I, al referirse el autor del Renacimiento a los humores, del pueblo y de los nobles respectivamente. El primero no quiere ser mandado y el segundo no quiere ser oprimido.

Desde la perspectiva de enfoque de este trabajo, Machiavelli no se está refiriendo en las citas anteriores a un mismo sujeto social, motivo por el cual no serían contradictorias. Las primeras cuatro citas y la última estarían reflejando la propia mirada del autor florentino sobre la generalidad de los hombres, mientras que las otras citas efectivamente sí se estarían refiriendo, al decir de Lefort, a la ciudad y a sus humores principales. En otras palabras, algunas de las citas textuales aluden al alma individual vista desde una perspectiva general y las otras al alma colectiva, al alma del grupo, al colectivo cohesionado a partir de lo afectivo. Tal vez así sea posible sostener que Machiavelli le otorga más importancia a los humores de la ciudad, como franco y aguzado pensador político que fue, que a una determinada concepción en torno a la naturaleza humana.

\section{La ciudad: campo dividido en deseos}

A los ojos del pensador de Florencia, la ciudad deviene un orden blindado, cerrado sobre sí mismo, "es una isla artificial constituida por medios violentos. No se abre a nada que está más allá de sí misma; solo es inteligible en relación con lo que la causa" $" 15$.

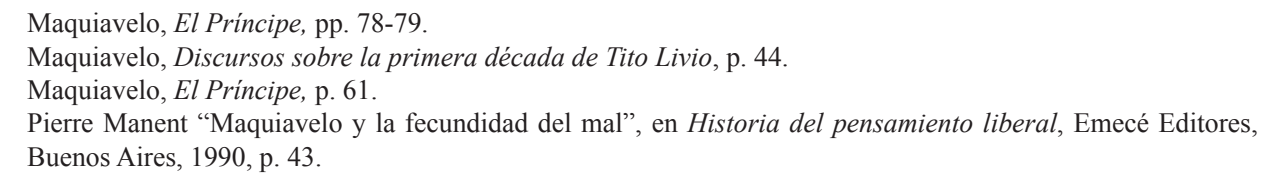


En toda ciudad entonces se presentan dos humores, según se afirmaba, el del pueblo y el de los nobles. Así lo expresa el florentino en los Discursos en el inicio del capítulo 39 del Libro I: "Se ve fácilmente, si se consideran las cosas presentes y las antiguas, que todas las ciudades y todos los pueblos tienen los mismos deseos y los mismos humores, y así ha sido siempre"16. El pueblo no quiere ser oprimido por los nobles y éstos quieren mandar y oprimir al pueblo.

En el deseo de no ser oprimido radica el principal mérito del pueblo a los ojos de Quentin Skinner; precisamente debido a su tendencia a la pasividad benigna ${ }^{17}$. El deseo del pueblo es, al fin y al cabo, inocente, afirma Machiavelli, es más honesto que el de los nobles. Pero se trata de una honestidad pasiva o negativa, la cual se presenta como un deseo de ausencia de opresión. Para Machiavelli ninguna acción es intrínsecamente buena; la bondad del mundo él la lee en la pasividad inocente de quienes de ordinario no actúan en claves políticas, vale decir el pueblo ${ }^{18}$.

Allí donde el pueblo se muestra capaz de resistir a la opresión de los nobles, el conflicto logra expresarse y de esta manera surgen buenas leyes para la ciudad. De los intereses contrapuestos, la sociedad logra alcanzar una tensión equilibrante. La oposición entre patricios y plebeyos, por ejemplo, es leída por Machiavelli como el factor vigorizante de la República romana.

Una vez reconocida esta división de la sociedad, entendida ésta como campo de conflicto entre y dentro de los grupos, la cual estudia Machiavelli en el capítulo IX de El príncipe, los análisis del florentino parecen ordenarse, según indica Lefort. Esta división, entre el pueblo y los grandes, ciertamente no es una división social de hecho — ricos/pobres — , sino de dos deseos en pugna: siguiendo a Lefort, el deseo de mandar/oprimir y el deseo de no ser mandado u oprimido. "Como se ve, ninguno de estos dos grupos tiene un fin positivo y bueno. Ninguno de estos dos grupos apunta a un bien"19.

Los nobles tienen un deseo de poseer sin límites, de indomeñable conquista. Frente a este deseo, el deseo del pueblo opera de efectivo freno. El pueblo desea vivir en un contexto de seguridad, mantener lo que posee y, sobre todo, no ser oprimido. Machiavelli se pregunta: ¿quién es ambicioso, el que quiere conquistar o el que quiere conservar lo que ya posee, entendiendo que ambos apetitos pueden ser causa de grandes conflictos?

Si se toma en cuenta la siguiente observación de Machiavelli, presente en los Discursos, en el capítulo 5 del primer Libro: “...a los hombres no les parece que posean con seguridad lo que tienen si no adquieren algo más" ${ }^{20}$, parecería entonces que ambos apetitos compelen a una búsqueda sin fin. Sin embargo, el autor sostiene que dichos apetitos son causados, la mayoría de las veces, por los que poseen, por los nobles, porque:

Más aún, sus maneras descorteses y soberbias encienden en el pecho de los desposeídos la ambición de poseer, o para vengarse de ellos despojándolos, o para acceder a esas riquezas y honores que ven mal empleados en los otros ${ }^{21}$.

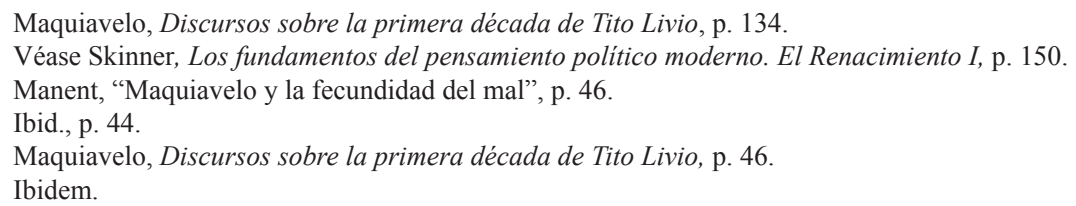


Para Machiavelli es indudable que los elementos del alma humana como deseos, pasiones en su realidad y efectividad, son sentimientos que pueden estudiarse, deviniendo objetos de conocimiento riguroso para el actor político, conocimiento que en El príncipe y en los Discursos se pone de manifiesto en sus variados análisis históricos y en las propias orientaciones suministradas al príncipe o fundador de una república. Este conocimiento queda desprovisto de explicaciones trascendentes. Los nobles, el pueblo, el propio príncipe, no persiguen objetivos trascendentes, trascendentes a sus propios intereses.

En Machiavelli se asoma una tesis sobre la constante insatisfacción del hombre. El hombre es primigeniamente un ser de deseo, "inclinado a apartarse de lo que tiene y de lo que es para aspirar a más" ${ }^{\prime 2}$ porque además, según se expresaba, no se tiene seguridad de lo poseído sino es en virtud de nuevas adquisiciones. Por ende, el deseo es insaciable, motivo por el cual el hombre terminará inexorablemente en un estado de insatisfacción constante.

Habría entonces una naturaleza deseante del hombre, "que se sitúa en los orígenes tanto de las insatisfacciones colectivas como de la inestabilidad política" ${ }^{" 23}$. El hombre, deslumbrado por la novedad, no tardará en hastiarse, aunque de su bienestar se trate. La insatisfacción humana es causa de búsqueda y es el efecto de la misma, puesto que hay algo que no se puede colmar, el mismo deseo.

Machiavelli afirma en los Discursos, en la segunda parte, que los apetitos son insaciables. Por naturaleza, no hay nada que el hombre no pueda desear, aunque en realidad no podemos lograr más que unas pocas cosas en esta vida. Por tal motivo, el espíritu humano está siempre disconforme, descontento. ¿Éste no es acaso el dilema que presenta la política? Bienes escasos, accesibilidad reducida a los bienes y ambiciones sin límites.

El deseo se presenta de dos formas: el deseo de adquirir por parte de quien tenga una falta y el miedo a perder lo que ya efectivamente se posee. Ahora bien, este último conduce en los nobles a oprimir, a los efectos de obtener nuevas adquisiciones, puesto que la seguridad de lo que se posee se logra en la adquisición de cosas nuevas. Estas ambiciones generan sentimientos en quienes no cuentan con bienes. Además del deseo de hacerse de ellos, estos sujetos sienten envidia por quienes sí cuentan con posesiones. Por su parte, los propietarios pueden sentir temor que los desposeídos los despojen de sus bienes, debiéndose asegurar de lo suyo adquiriendo nuevos bienes.

Indudablemente, los deseos constituyen verdaderas fuerzas dinamizadoras del cuerpo social y siempre dan cuenta de una falta. En un caso la falta es de bienes, en el otro de seguridad frente a los bienes poseídos. Los bienes, la propiedad en general, son claves con relación a la seguridad.

De lo expresado en los párrafos precedentes se desprende que para el autor florentino los hombres no titubearían en sacrificar su libertad en aras de su seguridad. "Les importa poco la libertad — el hombre les dice más que la realidad—y la colocan bien abajo de la seguridad, la propiedad o el deseo de venganza" ${ }^{24}$. De acuerdo a Machiavelli, los hombres preferían la seguridad de un falso mundo conocido a las ansiedades de un mundo en el cual emprender, afirma Sheldon S. Wolin (19222015), la penosa tarea del reajuste. Sigmund Freud (1856-1939), por su parte, lo

\footnotetext{
Ansart, Los clínicos de las pasiones políticas, p. 94.

Ibidem.

Berlin, "La originalidad de Maquiavelo", p. 101.
} 
expresa en estos términos: "El hombre culto ha cambiado un trozo de posibilidad de dicha por un trozo de seguridad" ${ }^{25}$. Es preferible, al parecer, limitar la dicha que, por no constreñirla, exponerse a la intemperie del mundo y sus embates.

En este sentido, la nueva ciencia de la política que se perfila en Machiavelli se orienta a desactivar las ilusiones que se interponen a los fines deseados en la acción política, adiestrando al actor político a construir y capitalizar las que fueran útiles para sus propósitos. La ciencia política deviene desenmascaradora de las falsas ilusiones que distorsionan una evaluación precisa de la situación política. Además, este conocimiento se propone instruir en el arte de fabricar ilusiones para llevar al enemigo a incurrir en errores letales.

En los Discursos Machiavelli sostiene que ningún sistema duradero se podía erigir sobre el pueblo, precisamente por su inestabilidad. Cuando un príncipe y el pueblo están sometidos a la ley, Machiavelli se inclina por el pueblo, pero cuando ninguno lo está, ambos eran perniciosos. ¿Por qué? Porque un pueblo habituado a vivir bajo el imperio de la ley se torna estable, obediente, agradecido. De ahí la virtud del pueblo; su sometimiento a la ley, mientras que "la virtud del príncipe tomaba necesariamente la forma de una destrucción creativa de leyes e instituciones. Por ello, en la etapa en que era factible un sistema republicano, la virtú heroica resultaba anacrónica" 26 .

Para refrenar los deseos de las masas, además de las disposiciones institucionales, Machiavelli pensaba en desarrollar una virtud cívica que marcó el fin de la alianza entre el arte de gobernar el Estado y el de gobernar las almas ${ }^{27}$, siendo la educación, la educación militar, las leyes y la religión aportes claves para su desarrollo. Todos estos recursos son disciplinadores, además, de las pasiones humanas.

\section{Psicología de las masas: algunos elementos en ciernes en Machiavelli}

A continuación, y a los fines de dar cuenta de la presencia de elementos vinculados a la psicología de las masas en el pensamiento del florentino, repasaré en primer lugar algunas consideraciones sobre la psicología de las masas según el psicoanálisis de Freud, para luego rastrear y analizar rastros precedentes en los textos de Machiavelli.

Es indudable la referencia obligada a Gustave Le Bon (1841-1931) respecto del análisis sistematizado del comportamiento colectivo. En su clásico libro La psicología de las multitudes o psicología de las masas (1895/1896), el autor francés afirmaba que en las aglomeraciones los rasgos propios del individuo se diluyen y emerge una suerte de alma colectiva que conduce a los miembros de un colectivo a sentir, pensar y actuar de un modo diferente a como cada uno lo haría de forma independiente. La masa, en principio, se explica por una variable cuantitativa; a saber, la cantidad de sus miembros que garantiza el solapamiento de la individualidad y la potencia para actuar. Una de sus características más destacadas, advierte Le Bon, es el contagio mental que produce debido a la capacidad que posee la masa para ejercer influencia en los pensamientos y actos de cada individuo. En la pertenencia

\footnotetext{
25 Sigmund Freud, "El malestar en la cultura" (1930), en Obras Completas. Vol. XXI, Amorrortu, Buenos Aires, 2006, p. 112.

26 Wolin, "Maquiavelo: Actividad política y economía de la violencia", p. 250.

27 Ibid., p. 256.
} 
a la masa, la personalidad consciente de sus miembros queda eclipsada por la emergencia del inconsciente.

Se torna especialmente interesante Le Bon, "el Maquiavelo de las sociedades de masas" como lo llama Serge Moscovici (1925-2014), porque es el primero, o tal vez uno de los primeros, en reconocer a Machiavelli como un predecesor en el estudio de los fenómenos colectivos.

La mayoría de las reglas relativas al arte de conducir a los hombres - escribe en 1910 - enseñadas por Maquiavelo, son desde hace mucho tiempo inutilizables, y sin embargo han pasado cuatro siglos sobre las cenizas de ese gran difunto, sin que nadie haya intentado rehacer su obra ${ }^{28}$.

Le Bon, el francés, es por lo expresado un nexo entre el florentino y el vienés. El texto mencionado de Le Bon, de enorme difusión, alcance y penetración, llega a las manos de Freud y se hace de él como punto de partida de sus investigaciones sobre la psicología colectiva. El mentor del psicoanálisis acepta la descripción de la masa llevada a cabo por Le Bon, así como también el papel fundamental que le otorga a los factores inconscientes en la explicación del comportamiento en masa. Asimismo, Freud también acuerda con Le Bon en que el individuo en tanto como parte de una masa desciende a un nivel emocional más primitivo.

Le Bon explica la metamorfosis que atraviesa el individuo en la masa por lo que él llama ligazón o unión, sin dar cuenta qué es lo que liga, une a los individuos entre sí. Entre los individuos de la masa, señala Le Bon, se opera un contagio, un fenómeno de índole hipnótico observable sin dificultad, pero difícil de aprehender, el cual lleva al individuo a sacrificarse en aras del interés colectivo. El efecto que Le Bon asocia al contagio es la sugestionabilidad. Ambos, contagio y sugestionabilidad, son presentados por el autor francés como causas de la transformación que sufre el individuo como parte de la masa. Freud invierte la relación entre ambos términos; el contagio es efecto de la sugestión y no al revés. El influjo sugestivo de la masa deviene la causa de la tendencia a caer en estados afectivos percibidos en otros - contagio o imitación-. A los efectos de tornar explicable la sugestión, las condiciones bajo las cuales ésta se produce, Freud apela al concepto de libido que se abordará más adelante.

Le Bon señala que el individuo en la masa adquiere un sentimiento de poder, de invencibilidad, el cual se liga a la falta de responsabilidad que facilita el anonimato. En este sentido, Freud marca una disidencia. Para el autor vienés el individuo en masa no adquiere rasgos nuevos por su pertenencia a ella. "Lo que sucede es que al hacer parte de la masa se encuentra en condiciones de echar por tierra las represiones de las mociones pulsionales inconscientes y en este contexto plantea una diferencia entre la concepción de Le Bon y la de él respecto al inconsciente"29. El vacío u olvido que advierte Freud en el despliegue teórico de Le Bon es la noción de lo reprimido inconsciente.

Entre el abordaje freudiano del fenómeno de masas y el maquiaveliano es dable hallar un punto de convergencia de índole "metodológico". Ambos autores son

28 Serge Moscovici, La era de las multitudes. Un tratado histórico sobre psicología de las masas, Fondo de Cultura Económica, México, 1985, p. 83.

29 Ángela María Jaramillo, "Freud y el estado de la cuestión. Psicología de las masas y análisis del yo": Affectio Societatis, vol. 4, n. ${ }^{\circ} 7$ (marzo de 2004), p. 3. 
agudos observadores de los hechos colectivos, ambos se sirven del material observacional para elaborar sus elaboraciones teóricas. "Freud ingresa al análisis de las masas no por la vía de la definición o concepto, sino por lo que él nombre "campo de fenómenos' a los que considera como fuente de 'hechos particularmente llamativos y característicos" "'30.

Los fenómenos de masa traen para el psicoanálisis experiencias de otro tiempo, de otro tiempo de la vida del sujeto y de la vida de la especie. Estos fenómenos dan cuenta de estructuras libidinales centradas en la figura simbólica del padre. En el análisis sobre las masas artificiales efectuado por Freud en Psicología de las masas y análisis del yo, a saber el ejército y la iglesia, es dable constatar la reedición de una relación heterónoma entre quien manda y quien obedece.

Se encuentra presente un jefe de la organización en estas instituciones, también subrogado del padre primordial, cuya presencia, al igual que su predecesor, constriñe y cohesiona. Ahora bien, estos actores sociales están gobernados (he aquí lo particularmente interesante para la reflexión política) por los afectos; son estructuras que están gobernadas por lazos afectivos, primordialmente, lazos que ligan a las partes entre sí y a éstas con el jefe. Esta trama de afecto, libidinal, es posible en estas organizaciones de masas merced a un cambio de meta de la libido o pulsión de amor. "Amar al jefe, adherir a él de preferencia a cualquier otro, será reproducir esa relación gratificante que se experimentó en la infancia y gracias a la cual se obtuvieron placer y protección" 31 .

La relación mando-obediencia en ambas organizaciones reedita la ambivalencia de los sentimientos de amor-odio; de amor a quien protege, a quien mancomuna, pero de hostilidad hacia él también en virtud de las interdicciones que esta figura de mando impone. Esta relación heterónoma actualiza un pasado afectivo sobre el cual se cimenta el presente, el presente de las relaciones sociales. En este sentido, la masa, reedición de un pasado individual y colectivo, es una suerte de actualización de la mítica horda primordial.

En la masa la conciencia del individuo queda atrofiada. Los individuos quedan, en función de esta operación, mancomunados inconcientemente y ligados a un pasado arcaico. Esta regresión es posible en función de una huella sobreviviente: “... la conservación del pasado en la vida anímica es más bien la regla que no una rara excepción" 32 .

La masa en tanto totalidad, restringe, limita el repliegue individual y permite la vincularidad del individuo, actualizando su ser social. Por ende, analizar el comportamiento de los grupos, investigando porqué los individuos se contagian del comportamiento de los demás y se limitan a repetirlo sin cuestionarse nada, ya sea en la vida política, religiosa, social, económica o la misma moda, ubica el foco de atención en el terreno de la psicología de las masas.

A continuación, el foco de análisis se ubica en algunos rasgos y conductas que tanto Freud como Le Bon atribuyen a las masas, y que, según se entiende, Machiavelli ya avizoraba en El príncipe y en los Discursos conforme a la lectura interpretativa de los textos maquiavelianos citados.

\footnotetext{
Ibid., p. 1.

Ansart, Clínica de las pasiones políticas, p. 201.

Freud, "El malestar en la cultura", p. 72.
} 
Machiavelli pareció advertir la ambivalencia en materia de sentimientos humanos cuando toma por objeto de análisis al pueblo. El amor y el odio constituyen sentimientos que se desprenden del carácter deseante del hombre. Pierre Ansart (19222016) lo explica de la siguiente forma:

...como el ser humano es esencialmente un ser de deseo y no de razón, hay que postular que las relaciones entre los hombres estarán cargadas de amor, desconfianza y odios (...). El deseo esencial de cada uno lo lleva a buscar bienes, adquisiciones, honores, y por lo tanto a rivalizar con otros para obtener más ${ }^{33}$.

En su mirada realista, el autor de Florencia sostiene que el amor es endeble, frágil y el odio se torna contraproducente. Por eso mismo prescribe el temor, como sentimiento que compele a la obediencia, a la sujeción y a la moderación en el caso de los nobles. El temor a la muerte o al castigo compele al hombre a hacer el bien; es decir, en otras palabras, el hombre se comporta bien por la necesidad de evitar un castigo. En palabras del florentino: “...los hombres por miedo al castigo, se conservan mejores y menos ambiciosos" 34 .

Siguiendo a Lefort, la necesidad que obliga a algo en general es necesidad impuesta por el miedo; éste compele a actuar contra nuestra propia inclinación natural.

Una característica de las masas es su maleabilidad. En Machiavelli está presente la idea del pueblo como una materia maleable, presta a adquirir la forma que el actor político le quiera dar. Al parecer, Machiavelli está persuadido de que la conducta del hombre es maleable por quien conoce la manera de sujetarlo al imperio de la necesidad.

La credulidad del pueblo facilita su maleabilidad. Cuyo juicio queda atrapado en el plano apariencial. Machiavelli afirma: "Pues los hombres, en general, juzgan más con los ojos que con las manos, porque todos pueden ver, pero pocos tocar. Todos ven lo que parece ser, mas pocos saben lo que eres" ${ }^{35}$. También afirma: “...porque el vulgo se deja engañar por las apariencias y por el éxito; y en el mundo solo hay vulgo, ya que las minorías no cuentan sino cuando las mayorías no tienen dónde apoyarse" ${ }^{96}$. En los Discursos el pensador de Florencia afirma algo similar:

Cualquiera que desee o necesite reformar el modo de gobierno de una ciudad, si quiere que el cambio sea aceptado y mantenido con satisfacción general, precisa conservar al menos la sombra de los usos antiguos, de modo que al pueblo no le parezca que ha cambiado el orden político, aunque de hecho los nuevos ordenamientos sean totalmente distintos de los pasados porque la mayoría de los hombres se sienten tan satisfechos con lo que parece como con lo que es, y muchas veces se mueven más por las cosas aparentes que por las que realmente existen"37.

El pueblo, al igual que la masa, no está atravesado por una sed de verdad. Al igual que la masa, el pueblo se conforma con ilusiones. La recomendación al príncipe en

\footnotetext{
Ansart, Los clínicos de las pasiones políticas, p. 106.

Maquiavelo, Discursos sobre la primera década de Tito Livio, p. 110.

Maquiavelo, El Príncipe, p. 112.

Ibidem.

Maquiavelo, Discursos sobre la primera década de Tito Livio, pp. 102-103.
} 
cuanto a satisfacer los deseos del pueblo ayuda a comprender más aun la manipulabilidad de este último.

Gustave Le Bon ${ }^{38}$ sostenía que la masa es siempre intelectualmente inferior al hombre aislado. Pero, desde el punto de vista de los sentimientos y de los actos que los sentimientos provocan, la masa puede según las circunstancias ser mejor o peor. Todo depende del modo en que la masa sea sugestionada.

En el capítulo IX de El príncipe, Machiavelli, además de señalar cierta docilidad del pueblo, señala su importancia para el arte político del propio príncipe, sobre todo para los principados basados en el consenso — principados civiles_-, principados preferidos por el autor debido a que el poder puede ser conservado sin necesidad de elevadas dosis de violencia.

Ahora bien, el pueblo no era solamente materia dócil y manipulable; era también fuerza impulsora, "y que esta energía, cuando la atraía el interés, podía ser convertida en un poder mayor que el de cualquier otro sistema" 39 .

Un elemento clave de la psicología de las masas es la presencia de un líder o jefe, el cual en El príncipe este lugar estaría reservado al propio príncipe, aquél actor de quien depende el porvenir del Estado. "Una condición de la coordinación de las iras individuales es, para Maquiavelo, la existencia de un jefe, un representante, que asegure la continuidad y la unificación de los sentimientos individuales" ${ }^{40}$. En los Discursos, a diferencia de en El príncipe, el lugar del líder, del jefe, está puesto en la figura del fundador. En El príncipe el acento está puesto en formatear la conducta del propio príncipe; en los Discursos el foco está puesto en modelar al conjunto de ciudadanos.

En el capítulo 26 de los Discursos, Machiavelli afirma que la sociedad política más deseable depende de la habilidad de un hombre fuera de lo común que transforme una materia corrompida en otra de naturaleza opuesta. La principal fortuna de una república está en su fundador y no en la acción de las masas. El héroe político, que no sea el fundador, legislador, no tiene mayor peso en esta obra. Para generar nuevas instituciones o reconstruir las viejas se requiere de un hombre extraordinario. En el mismo texto, Machiavelli afirma que la multitud es inútil si no tiene una cabe$\mathrm{za}^{41}$ y también afirma en la misma obra, en el capítulo 54 del Libro I, que "nada es tan apropiado para poner freno a una multitud reunida, como el respeto a un hombre grave y de autoridad que les haga frente" 42 .

El pueblo es quien más se ajusta a la noción de masa en términos del psicoanálisis freudiano, corriente para quien el líder de ésta representaría el retorno del padre primordial, el cual se erige en ideal de la masa gobernando al yo en reemplazo del Ideal del yo. El príncipe podría ocupar el lugar del padre primordial, separándose así de la masa. "El conductor de la masa sigue siendo el temido padre primordial"43.

Es pertinente aclarar que la noción de pueblo en Machiavelli no es plenamente intercambiable con la noción freudiana de masa. Conforme se irá desplegando a con-

\footnotetext{
Véase Gustave Le Bon, Psicología de la masas, Morata, Madrid, 2005.

Wolin, "Maquiavelo: Actividad política y economía de la violencia", p. 254.

Ansart, Los clínicos de las pasiones políticas, p. 101.

Véase Maquiavelo, Discursos sobre la primera década de Tito Livio, p. 144.

Ibid., p. 166.

43 Sigmund Freud, "Psicología de las masas y análisis del yo" (1921), en Obras Completas. Vol. XVIII, Amorrortu, Buenos Aires, 2004, p. 121. La noción de padre primordial o padre de la horda primitiva es desarollada por el autor vienés en Sigmund Freud, “Tótem y tabú" (1912-1913), en Obras Completas. Vol. XIII, Amorrortu, Buenos Aires, 2003.
} 
tinuación, este trabajo pretende señalar elementos similares, convergentes en ambas nociones.

A los fines de cotejar los términos de pueblo y masa es importante revisar la idea moderna de individuo presente en el florentino como en Freud, de forma tal de apreciar puntos de encuentro y desencuentro. Machiavelli no ha trascendido por sus estudios sobre la psique. Sin embargo, en el florentino es dable relevar una determinada concepción del hombre y, como se expresó anteriormente, una cierta "teoría psicológica". El autor de El príncipe concibe al individuo, conforme a sus agudas observaciones empíricas y al estudio de la historia, como un ser dual que se debate entre su humanidad y su animalidad, entre su razón e impulsos instintivos. A diferencia de Freud, la interpretación que lleva a cabo Machiavelli se ciñe al hombre político, al hombre en tanto condición política. En rigor de verdad, el análisis de la realidad y de la historia que lleva a cabo Machiavelli es llevado a cabo a través del prisma de la vida política. Un conjunto de pasiones, sentimientos, apetitos es parte constitutiva del núcleo esencial del humano, el cual es advertido por el florentino en el estudio de la vida política. Estas fuerzas constituyen un elemento inalterable y dominante respecto de la parte racional. El afán insaciable de poder es el apetito presente en las guerras, disputas políticas, fundaciones de Estados. En virtud de esta naturaleza inalterable es que Machiavelli puede concebir al hombre en cualquier tiempo y espacio en los mismos términos, independientemente de la dinámica de los hechos históricos. Reconocer este componente inalterable, inherente al alma humana, es propio del enfoque realista de Machiavelli, enfoque desde el cual las consideraciones morales e idealizaciones sobre el hombre no tienen cabida. En síntesis, Machiavelli presenta una versión desencantada del hombre, concibiéndolo en tanto mecanismo de fuerzas o impulsos - odio, temor, amor, apetito de poder-, fuerzas que pueden ser gestionadas por quien efectivamente conozca el mundo psíquico del hombre sin el recubrimiento idealizado de su naturaleza.

Freud comparte con el florentino una concepción del hombre semejante. Ambos piensan un ser en conflicto con su propia naturaleza, conflicto entre la razón o consciencia, entre las fuerzas de índole más instintiva o inconsciente. Tanto uno como otro contribuyen a esculpir la imagen de un hombre habitado por potentes impulsos, los cuales, librados a su suerte, tienen mayor incidencia en el gobierno de la vida humana que la razón o la consciencia.

Desde luego que si el jefe de la masa, el príncipe, ocuparía ese lugar es de acuerdo a una interpretación psicoanalítica en virtud de la existencia de una huella en el presente, la cual pervive en la memoria filogenética. Esa huella se expresa como añoranza simbólica del padre. Frente al hiperpoder de la naturaleza, frente a la fragilidad organísmica y a la insuficiente capacidad de la norma para regular la convivencia, el individuo añora regulación, protección; demanda ley.

Ambos textos, El príncipe y los Discursos, se refieren al pueblo. La diferencia entre ellos, al decir de Sheldon S. Wolin, radica en una mayor apreciación por parte de Machiavelli de las capacidades políticas de las masas, haciendo prescindible la figura del héroe político. La transición a un nuevo tipo de virtud que implicara una orientación hacia la masa y una desvinculación con respecto a la actividad heroica del actor político, supone redefinir la virtud del príncipe: un príncipe prudente sería aquel que ordenara al estado de tal forma que éste pueda seguir existiendo tras su muerte. En palabras de Machiavelli: "Y desde luego podemos llamar feliz a aquella república en la que haya surgido un hombre tan prudente que le haya dado leyes ordenadas de tal manera que, sin necesidad de corregirlas, pueda vivir segura bajo 
ella"44. Más adelante, el autor agrega: "No es la salvación de un reino o de una república tener un príncipe que gobierne prudentemente mientras viva, sino uno que lo organice todo de manera que, aún después de muerto, se mantenga" ${ }^{45}$.

En El príncipe, su autor sostiene que el príncipe no puede hacer descansar su poder sobre el pueblo y los nobles respectivamente, debido al reciproco enfrentamiento entre ambos grupos. Machiavelli recomienda al príncipe obtener la aprobación del pueblo, precisamente porque éste era más fácilmente dominable, maleable. Los nobles poseían un deseo insaciable de poder, de dominio, motivo por el cual ningún príncipe podría satisfacerlos con seguridad en el largo plazo. En los Discursos, en el capítulo 37, su autor afirma: “...porque es tanta la ambición de los grandes, que, si no es abatida por varias vías y procedimientos, pronto conduce a la ciudad a la ruina" ${ }^{46}$. El pueblo, quien solo pide no ser oprimido, encarna, afirma Lefort, un deseo de libertad. En palabras de Machiavelli:

Pero por lo que respecta al otro deseo popular de recuperar la libertad, no pudiendo el príncipe satisfacerlo, debe analizar por qué razones quieren ser libres, y encontrará que una pequeña parte quiere ser libre para mandar, pero todos los demás, que son infinitos, desean la libertad para vivir seguros ${ }^{47}$.

El deseo del pueblo de no ser oprimido podría ser atendido por el príncipe garantizando tan solo la seguridad de la propiedad y de la familia. En cambio, la ambición de dominio de los nobles no se podía alcanzar sin perjudicar a otros, como el propio autor indica. Al respecto, son elocuentes las palabras del mismo Machiavelli: "Porque la mayoría de los hombres, mientras no se vean privados de sus bienes y de su honor, viven contentos; y el príncipe queda libre para combatir la ambición de los menos que puede cortar fácilmente, y de mil maneras distintas"48. De esa manera, la base más segura para conservar el poder para el príncipe reside en el pueblo, cuya pretensión es solo mantener sus posesiones, a diferencia de la nobleza que ambiciona sin límites. Machiavelli, como bien afirma Wolin, creía que la disconformidad era el vicio de los nobles, cuya aspiración era la dominación total.

La conformación de un pueblo implicaría que cada individuo que lo integra sea capaz de sacrificar sus intereses personales, operándose desde la perspectiva del psicoanálisis una atrofia de la personalidad individual consciente. Desde luego, algo gana en este sacrificio. Y lo que gana es protección al adquirir un sentimiento de poder invencible que le permite echar por tierra la represión de sus mociones pulsionales.

El pueblo, obediente ante la autoridad, es quien puede aceptar un líder más allá de los sacrificios que éste imponga a los intereses particulares. Al jefe político el pueblo le pedirá gestos de fortaleza, de gallardía. El deseo del pueblo y el propio del príncipe son compatibles. No ocurre lo mismo entre el deseo de los nobles y del príncipe. Los nobles no aceptan una autoridad en el largo plazo. Como afirma Machiavelli con relación a los nobles: “...porque los que lo rodean se consideran sus iguales, y en tal caso se le hace difícil mandarlos y manejarlos como quisiera" 49 . Pero además,

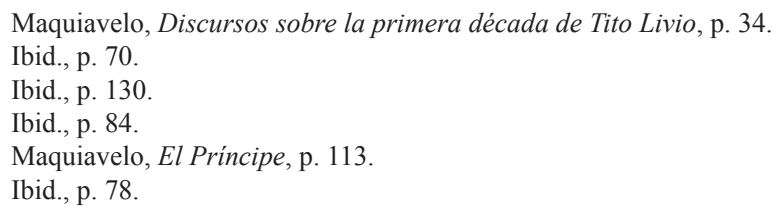


"los nobles son más astutos y clarividentes, siempre están a tiempo para ponerse a salvo, a la vez que no dejan nunca de congratularse con el que esperan resultará vencedor" ${ }^{50}$. A continuación, el autor agrega: "Mientras que el que llega por el favor popular es única autoridad, y no tiene en derredor a nadie o casi nadie que no esté dispuesto a obedecer"51.

La ambición política del príncipe y la demanda de preferencia de los nobles es difícil de armonizar; en cambio, el deseo del pueblo y la ambición principesca, entendida como búsqueda de gloria, efectivamente son armonizables. El príncipe y el pueblo representan entonces dos deseos o pasiones conciliables. El primero podía hallar su gloria personal poniendo en acto su virtú al generar un estado de paz y orden que responda al deseo de seguridad del pueblo, convirtiéndose, además, en la pieza política clave para eliminar la corrupción, la cual necesita de talentos heroicos cuando se hace presente.

Otros elementos que permiten apreciar cierta semejanza entre la noción de pueblo en Machiavelli y la masa de acuerdo a la concepción del psicoanálisis es la presencia en el pueblo de sentimientos simples, como su inclinación a juzgar según las apariencias, por no prestarse a cavilaciones y dudas lógicas, entre otros.

\section{Algunas consideraciones finales}

El interés fundamental de Machiavelli es sin duda el Estado, principalmente su fundación y conservación. El análisis que el autor despliega en torno a la conducta humana en los textos seleccionados no sirve más que a ese fin. En este sentido, el conocimiento de la psicología está al servicio de la política. Sus observaciones respecto de la vida psíquica del hombre son llevadas a cabo a partir de centrar la mirada en los comportamientos humanos de la vida política, presente y pretérita.

Al ubicar el foco de atención sobre la ciudad, el florentino advierte que el orden político está polarizado en dos grupos que expresan dos deseos en pugna; a saber el deseo de mandar y oprimir por parte de los nobles, y el deseo de no ser oprimidos por parte del pueblo. Es en la fricción entre ambos deseos donde Machiavelli ve el equilibrio político deseable.

Ciertos elementos inherentes a la noción freudiana de psicología de las masas se visibilizarían en Machiavelli, aunque con cierto carácter embrionario. Entre ellos se destaca la caracterización que lleva a cabo el florentino de pueblo, caracterización que se aproximaría en algunos aspectos a la noción de masa según el enfoque psicoanalítico de Freud.

La presencia de una ambivalencia de sentimientos en el pueblo, el ser éste objeto maleable, presto a adquirir la forma que el líder político desee cincelarle si efectivamente sabe cómo sujetarlo al imperio de la necesidad, darían en parte cuenta de ello. El pueblo, al igual que la masa para Freud, es manipulable. Su credulidad se explica por el despliegue de un juicio que queda confinado al plano aparencial, razón por la cual el pueblo es un colectivo manejable, y además de dúctil, el pueblo es más honesto y modesto en materia de deseo; solo desea no ser oprimido. Su deseo y el del príncipe no entran en discordia. Además de su docilidad, credulidad y manipu-

\footnotetext{
Ibid., p. 79.

51 Ibid., p. 78.
} 
labilidad, el pueblo es a los ojos del autor de El príncipe fuerza impulsora para el orden político en aras de su conservación. El pueblo, a diferencia de los nobles que constituyen una minoría, es quien puede acatar la autoridad. El pueblo requiere de dirigentes fuertes que le brinde seguridad, protección.

Machiavelli no explica, a diferencia de Freud, la transformación psíquica que afecta al individuo en tanto parte de una masa. El pensador de Florencia tampoco explica la obediencia política del pueblo al líder en los términos que lo hace Freud, es decir como obediencia al padre mítico de la horda a través de sus figuras subrogadas. El líder político, conforme a la explicación de Freud, ocupa el lugar del padre primordial, separándose así de la masa. Si este actor puede ocupar este lugar es debido a la existencia de una huella filogenética que se activa en el presente y se expresa como añoranza del padre asesinado. De esta manera, la obediencia al gobernante es obediencia de efecto retroactivo al padre depuesto. Conforme a este mito, tras el acto criminal contra el despótico padre aflora el arrepentimiento y la conciencia de culpa colectivos. La hostilidad y la violencia hacia el padre se dirigen luego de la gesta parricida hacia el yo en forma de culpa. "Esta culpa tiene como consecuencia la obediencia retrospectiva del mandato paterno" 52 .

¿Qué explicación aporta Machiavelli respecto de la obediencia del pueblo al conductor político? ¿Por qué se obedece en política? Explicar la obediencia política en función de la menguada ansía de poder del pueblo se revela insuficiente. El pueblo obedece al gobernante en parte por el temor al castigo y en parte por amor a su figura señala Machiavelli. Dada la improbabilidad de reunir en torno a una misma figura política el amor y el temor, es decir que un líder sea temido y a la vez amado, el autor no titubea en indicarle al príncipe que se apoye en el temor. El amor es un sentimiento lábil, quebrantable cuando no se obtiene lo que se desea o espera. Por el contrario, el temor, que no es otra cosa que temor al castigo, es un sentimiento que sujeta a la obediencia, deviniendo apoyo seguro para el ejercicio del poder público. ¿Acaso la gesta de los hermanos contra el padre de la horda no pone de manifiesto lo ya observado por Machiavelli: la labilidad del amor y la necesidad del temor en aras de la obediencia? En Freud se encuentra, a diferencia del florentino, la culpa como factor explicativo de la obediencia.

Si bien la concepción de pueblo en Machiavelli permite detectar algunas similitudes con la concepción de masa llevada a cabo por Freud, no por ello pueblo y masa constituyen conceptos idénticos, intercambiables. No obstante, el encuentro de algunas semejanzas entre ambas nociones permitiría considerar al florentino como un antecedente cabal de lo que más tarde, y en virtud de los desarrollos de Le Bon y Freud principalmente, tomará cuerpo como psicología de las masas. Le Bon reconoce al pensador de Florencia como un predecesor suyo en este terreno. ¿Es posible atribuirle el mismo reconocimiento al mentor del psicoanálisis? 52 Ángel Rodríguez Kauth y Mabel Inés Falcón, "Desarrollos en Psicoanálisis y Política”: Psicología Política, n.
17 (1998), p. 88. 


\section{Referencias bibliográficas}

Ansart, Pierre, Los clínicos de las pasiones políticas, Ediciones Nueva Visión, Buenos Aires, 1997.

Berlin, Isaiah, "La originalidad de Maquiavelo", en El estudio adecuado de la humanidad. Antología de Ensayos, Fondo de Cultura Económica, Madrid, 2009.

Freud, Sigmund, “Tótem y tabú” (1912-1913), en Obras Completas. Vol. XIII, Amorrortu, Buenos Aires, 2003.

_., "Psicología de las masas y análisis del yo" (1921), en Obras Completas. Vol. XVIII, Amorrortu, Buenos Aires, 2004.

—, "El malestar en la cultura" (1930), en Obras Completas. Vol. XXI, Amorrortu, Buenos Aires, 2006.

Jaramillo, Ángela María, "Freud y el estado de la cuestión. Psicología de las masas y análisis del yo": Affectio Societatis, vol. 4, n. 7 (marzo de 2004), pp. 1-8.

Le Bon, Gustave, Psicología de la masas, Morata, Madrid, 2005.

Lefort, Claude, El arte de escribir y lo político, Herder, Barcelona, 2007.

Manent, Pierre, "Maquiavelo y la fecundidad del mal", en Historia del pensamiento liberal, Emecé Editores, Buenos Aires, 1990.

Maquiavelo, Nicolás, El Príncipe, Editores Mexicanos Unidos S.A., Buenos Aires, 1989.

—, Discursos sobre la primera década de Tito Livio, Alianza Editorial, Madrid, 2003.

Moscovici, Serge, La era de las multitudes. Un tratado histórico sobre psicología de las masas, Fondo de Cultura Económica, México, 1985.

Rodríguez Kauth, Ángel y Falcón, Mabel Inés, "Desarrollos en Psicoanálisis y Política": Psicología Política, n. ${ }^{\circ} 17$ (1998), pp. 79-100.

Skinner, Quentin, Los fundamentos del pensamiento político moderno, Fondo de Cultura Económica, México, 1985.

Wolin, Sheldon S., "Maquiavelo: Actividad política y economía de la violencia", en Política y perspectiva. Continuidad y cambio en el pensamiento político occidental, Amorrortu, Buenos Aires, 1960. 